\title{
Cardiovascular benefits of sodium-glucose cotransporter 2 inhibitors in diabetic and nondiabetic patients
}

\author{
Boyang Xiang, Xiaoya Zhao and Xiang Zhou*
}

\begin{abstract}
Sodium-glucose cotransporter 2 inhibitors (SGLT2i) were developed as antidiabetic agents, but accumulating evidence has shown their beneficial effects on the cardiovascular system. Analyses of the EMPA-REG OUTCOME trial (Empagliflozin Cardiovascular Outcome Event Trial in Type 2 Diabetes Mellitus Patients) suggested that these benefits are independent of glycemic control. Several large-scale outcome trials of SGLT2i also showed cardiovascular benefits in nondiabetic patients, strengthening this perspective. Extensive animal and clinical studies have likewise shown that mechanisms other than the antihyperglycemic effect underlie the cardiovascular benefits. Recent clinical guidelines recommend the use of SGLT2i in patients with type 2 diabetes mellitus and cardiovascular diseases because of the proven cardiovascular protective effects. Since the cardiovascular benefits are independent of glycemic control, the therapeutic spectrum of SGLT2i will likely be extended to nondiabetic patients.
\end{abstract}

Keywords: Sodium-glucose cotransporter 2 inhibitors, Cardiovascular benefits, Diabetes

\section{Introduction}

Sodium-glucose cotransporter 2 inhibitors (SGLT2i) are antidiabetic drugs that lower blood glucose levels in patients with type 2 diabetes mellitus (T2DM). SGLT2i decrease renal glucose reabsorption by blocking SGLT2 and thus enhance the urinary excretion of glucose [1]. Their mechanism of action differs from those of traditional antihyperglycemic interventions, which attenuate insulin sensitivity, preserve $\beta$-cell function, or increase tissue glucose uptake.

The concept of SGLTs was first proposed in the 1960s [2] and, during the ensuing decades, six SGLT subtypes, of which SGLT1 and SGLT2 are the most important, were discovered in the human body. SGLT1, which has high affinity and low transport capacity for glucose,

*Correspondence: zhou-xiang@suda.edu.cn

Department of Cardiology, The Second Affiliated Hospital of Soochow University, No. 1055 Sanxiang Road, Suzhou 215004, People's Republic of China is present in the intestine, kidney, heart, prostate, trachea, brain, and skeletal muscle whereas SGLT2, which has low affinity and high transport capacity for glucose, is located almost exclusively in the epithelium of the proximal tubular segment [3-5]. In healthy individuals, almost all filtered glucose (approximately $160-180 \mathrm{~g}$ per day) undergoes tubular reabsorption [6]; most $(>90 \%)$ is reabsorbed by SGLT2 in the proximal tubule and the remainder $(<10 \%)$ is reabsorbed by SGLT1 in more distal segments of the proximal tubule $[4,5,7]$. However, because of a compensatory increase in SGLT1-mediated transport [8], or other latent factors, complete pharmacological blockade of SGLT2 only leads to urinary excretion of $50-80 \mathrm{~g}$ of glucose per day (i.e., SGLT2i block $<50 \%$ of renal glucose reabsorption) in healthy individuals [4] and this level of SGLT2i-mediated glycosuria does not increase even in those with diabetes mellitus $[9,10]$.

In addition to improving glycemic control, a growing body of clinical evidence has shown that SGLT2i provide remarkable cardiovascular benefits, most notably 
a reduced risk of hospitalization for heart failure (HF). These benefits occur rapidly and persist throughout treatment, which is inconsistent with the slow effect of glycemic control on the cardiovascular system [11, 12]. In the EMPA-REG OUTCOME trial (Empagliflozin Cardiovascular Outcome Event Trial in Type 2 Diabetes Mellitus Patients), which included individuals with T2DM and cardiovascular diseases (CVD), only a modest correlation was observed between changes in HbA1c (glycosylated hemoglobin) and amelioration of cardiovascular outcomes, suggesting that the cardiovascular benefits of empagliflozin might be independent of its antihyperglycemic effect $[13,14]$. Recently, several largescale randomized controlled trials of SGLT2i have likewise demonstrated cardiorenal benefits in nondiabetic patients [15-17].

In this review, we focus mainly on the cardiovascular benefits of SGLT2i, the underlying mechanisms, and prospects for clinical application.

\section{Cardiovascular benefits of SGLT2i}

Currently, four SGLT2i (empagliflozin, dapagliflozin, canagliflozin, and ertugliflozin) are licensed by the European Medicines Agency (EMA) and the US Food and Drug Administration (FDA). Several other SGLT2i (e.g., sotagliflozin, remogliflozin, ipragliflozin, and tofogliflozin) have progressed to marketing approval in different regions. Table 1 lists nine large-scale cardiorenal outcome trials of SGLT2i published in the last five years, showing the baseline characteristics of individuals enrolled, interventions, and cardiovascular outcomes.

Across the whole patient population (including individuals without T2DM), these randomized controlled trials all demonstrated the cardiovascular benefits of SGLT2i, most notably a remarkable reduction in the risk of hospitalization for HF (Fig. 1), and indicated the involvement of mechanisms other than glycemic control. In addition to improved prognosis, quality of life also improved in patients with HF and reduced ejection fraction (HFrEF), as indicated by improved Kansas City Cardiomyopathy Questionnaire (KCCQ) scores.

\section{Empagliflozin}

The EMPA-REG OUTCOME trial [18] in patients with T2DM and CVD demonstrated that empagliflozin, as compared with placebo, decreased the risk of major adverse cardiovascular events (MACE), an effect that was principally ascribed to a significant reduction in risk of death from cardiovascular causes. Both the risk of hospitalization for HF and death from any cause were also markedly reduced by treatment with empagliflozin. Interestingly, a similar decrease in risk of MACE was observed in the two different dose groups in the trial, probably signifying a small dose-response relationship between the dose of empagliflozin and cardiovascular benefits. However, a marked correlation between changes in $\mathrm{HbA} 1 \mathrm{c}$ and drug dose was observed, implying the involvement of mechanisms other than glycemic control in the cardiovascular benefits. This was later confirmed in several analyses of the EMPA-REG OUTCOME trial $[13,14]$.

The EMPEROR-Reduced trial (Empagliflozin Outcome Trial in Patients with Chronic Heart Failure and a Reduced Ejection Fraction) [15] in patients with HFrEF, together with New York Heart Association class II-IV symptoms, showed that empagliflozin, as compared with placebo, reduced the composite risk of hospitalization for worsening HF or death from cardiovascular causes, mainly driven by the reduced risk of the former, and increased KCCQ score at 52 weeks. The effects were of similar size whether diabetes was present or not, again revealing a cardiovascular benefit beyond the antidiabetic effect. As compared with other similar studies, the EMPEROR-Reduced trial extended the known cardiovascular protection of SGLT2i to patients with more advanced but stable HF.

\section{Canagliflozin}

In the CANVAS (Canagliflozin Cardiovascular Assessment Study) program [19], the risk of MACE in patients with T2DM and CVD or multiple cardiovascular risk factors was reduced by treatment with canagliflozin, albeit without a significant decrease in death from cardiovascular causes or death from any cause. The CREDENCE (Canagliflozin and Renal Events in Diabetes with Established Nephropathy Clinical Evaluation) trial [20], which involved patients with chronic kidney disease (CKD) and T2DM, showed that treatment with canagliflozin improved the composite primary endpoint of end-stage kidney disease, doubling of serum creatinine level, or death from cardiorenal causes. Both trials indicated that canagliflozin markedly decreased the risk of hospitalization for HF. An analysis of the CREDENCE trial also found that the cardiorenal benefits were independent of glycemic control [21].

\section{Dapagliflozin}

The DECLARE-TIMI 58 (Dapagliflozin Effect on Cardiovascular Events-Thrombolysis in Myocardial Infarction 58) trial [22], which involved individuals with T2DM and atherosclerotic CVD (ASCVD) or a high risk of ASCVD, demonstrated a remarkable reduction in risk of hospitalization for HF in the dapagliflozin group compared with the placebo group. The reduction in risk of MACE, death from cardiovascular causes, and death from any cause did not, however, reach statistical significance. In a 


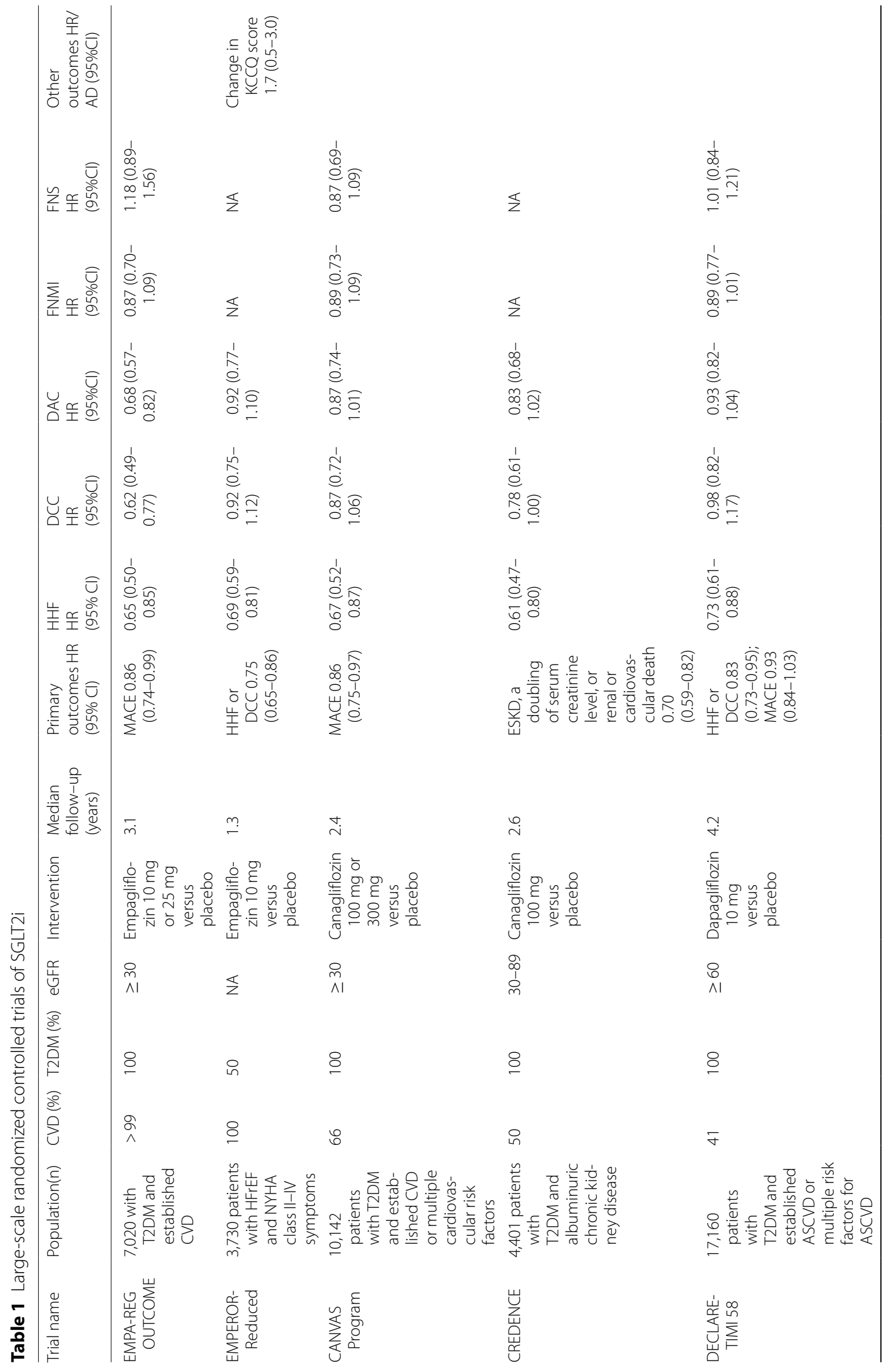




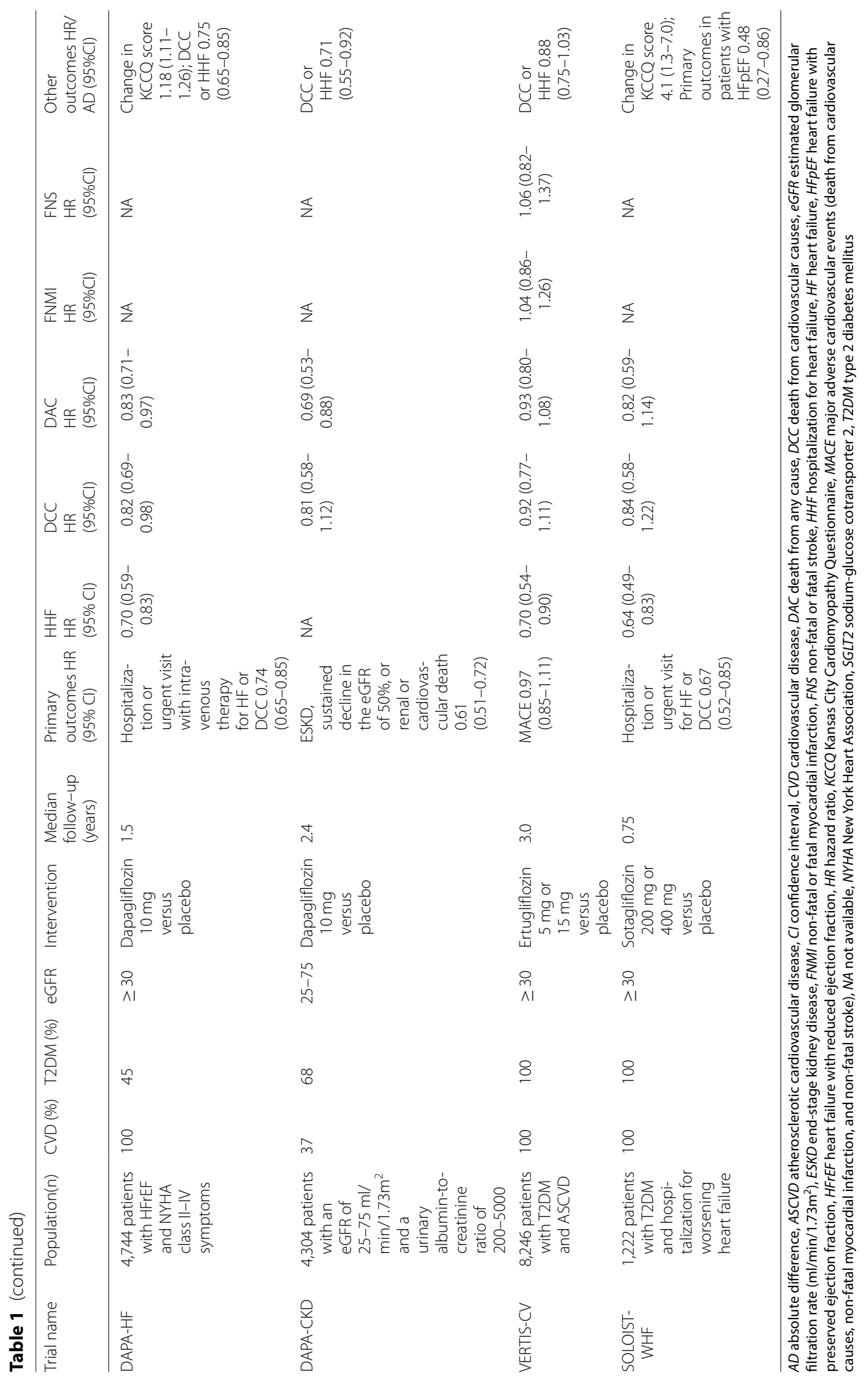




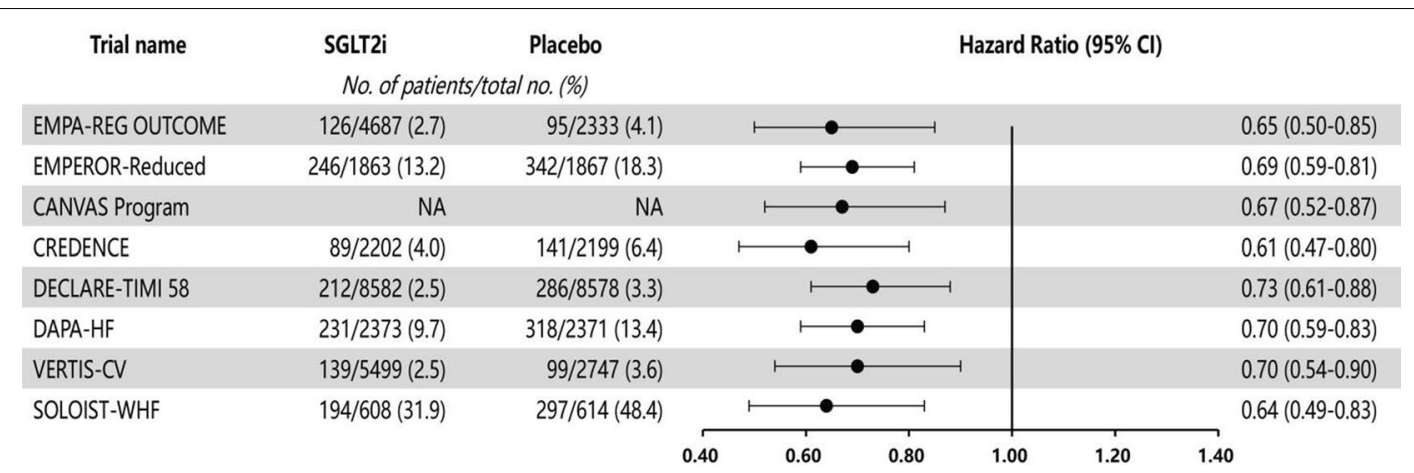

Fig. 1 SGLT2i reduce the risk of hospitalization for heart failure in large randomized controlled trials. With SGLT2i therapy, the reduction in risk of hospitalization for heart failure was consistent and significant across different patients. Cl, confidence interval; NA, not available

prespecified study of the DECLARE-TIMI 58 trial, dapagliflozin therapy showed cardiovascular benefits, regardless of levels of biomarkers of myocardial injury and HF (including high sensitivity troponin $\mathrm{T}$ and $\mathrm{N}$-terminal pro-brain natriuretic peptide), with more benefits seen in patients with more severe CVD [23]. The DAPA-HF (Dapagliflozin and Prevention of Adverse Outcomes in Heart Failure) trial [16], which involved patients similar to those in the EMPEROR-Reduced trial [15], showed that dapagliflozin provided similar cardiovascular benefits to empagliflozin. The DAPA-CKD (Dapagliflozin and Prevention of Adverse Outcomes in Chronic Kidney Disease) trial [17], which involved patients with an estimated glomerular filtration rate (eGFR) of 25-75 ml/ $\min / 1.73 \mathrm{~m}^{2}$ and albuminuria, showed that treatment with dapagliflozin led to a reduction in the combined risk of end-stage kidney disease, a decline of $\geq 50 \%$ in eGFR, or death from cardiorenal causes, regardless of T2DM. All-cause mortality and the composite risk of death from cardiovascular causes or hospitalization for HF were also reduced.

\section{Other SGLT2 inhibitors}

The VERTIS-CV (Evaluation of Ertugliflozin Efficacy and Safety Cardiovascular Outcomes) trial [24], which recruited patients with T2DM and established ASCVD, showed that ertugliflozin, as compared with placebo, only reduced the risk of hospitalization for HF, without significant reduction in risk of MACE, death from cardiovascular causes, or other cardiovascular outcomes. The reason why the results of the trial did not reach statistical significance remains unclear.

The SOLOIST-WHF (Effect of Sotagliflozin on Cardiovascular Events in Patients with Type 2 Diabetes Post Worsening Heart Failure) trial [25] showed that sotagliflozin, an SGLT2i that also inhibits gastrointestinal SGLT1 to some extent, decreased the risk of death from cardiovascular causes or hospitalization and urgent visits for HF in patients with T2DM and recent hospitalization for worsening HF. Treatment with sotagliflozin also increased the KCCQ score, but the trial was stopped earlier than planned due to loss of funding from the sponsor, which probably limited the statistical power to evaluate some outcomes, such as cardiovascular death.

\section{Cardiovascular protection mechanisms of SGLT2i}

The cardiovascular benefits of SGLT2i are mediated by multiple direct and indirect mechanisms that are interwoven and interactional (Fig. 2). These mechanisms improve many aspects of the cardiovascular system, including hemodynamics, metabolism, oxidative stress, and inflammation.

\section{Glycemic control and attenuation of glucotoxicity}

Clinical studies in patients with T2DM have suggested that SGLT2i, as compared with placebo, decrease HbA1c by $0.6-1.0 \%$ in the presence of different background therapies [26-28]. Although it remains controversial whether SGLT2i can be combined with insulin to treat type 1 diabetes mellitus (T1DM) because of safety issues, recent meta-analyses of clinical trials have demonstrated a reduction in HbA1c levels of approximately $0.4 \%$ in patients with T1DM [29, 30]. The antihyperglycemic effect of SGLT2i depends on urinary glucose excretion and, in patients with CKD, the effect is thus diminished as eGFR decreases [31]. In the CREDENCE trial, the blood glucose lowering effect weakened over time, whereas the cardiovascular benefits did not [20], indicating that glycemic control does not account for the cardiorenal benefits of SGLT2i.

Because urinary glucose levels are elevated, the most common adverse event of SGLT2i is genital infections, with a higher incidence in females than in males [32]. SGLT2i generally do not lead to hypoglycemia [16-19, 


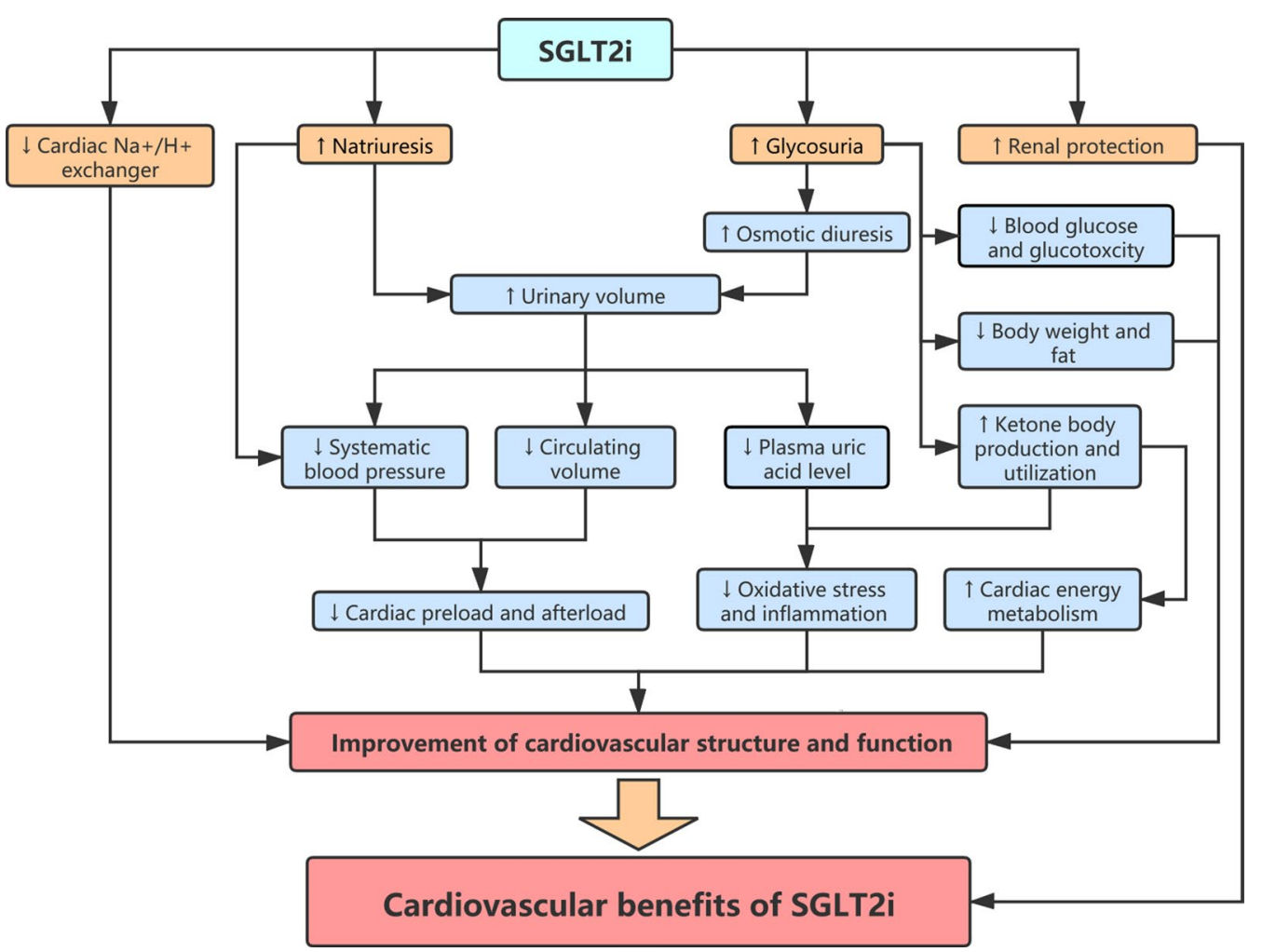

Fig. 2 Cardiovascular protection mechanisms of SGLT2i. SGLT2i directly increase natriuresis and glycosuria, leading to a spectrum of secondary beneficial effects on the cardiovascular system. Inhibition of the cardiac $\mathrm{Na}^{+} / \mathrm{H}^{+}$exchanger and protection of renal function mediated by SGLT2i may also, to some extent, play a beneficial role. These effects jointly contribute to the cardiovascular benefits of SGLT2i, especially the reduced risk of hospitalization for heart failure

22], unless combined with drugs that cause hypoglycemia, such as sulfonylureas [33].

As well as reducing blood glucose, SGLT2i also decrease glucotoxicity, which is manifest as reduced generation of advanced glycation end products (AGEs) and reduced expression of receptors for advanced glycation end products (RAGEs). AGEs are an assortment of heterogeneous compounds that are produced via non-enzymatic glycation and oxidation of proteins, lipids, and nucleic acids [34]. RAGEs are present on the surface of numerous different cardiovascular cells, including smooth muscle cells, endothelial cells, cardiomyocytes, and immune cells, such as monocytes/ macrophages and $\mathrm{T}$ lymphocytes [35]. Accumulating evidence shows that AGEs mediate detrimental effects on the cardiovascular system by two main mechanisms: crosslinking of tissue proteins and activation of AGE-RAGE signaling pathways [36, 37]. AGEs contribute to vascular stiffness and myocardial fibrosis by crosslinking tissue collagen and elastin [38-40] and enhance oxidative stress and inflammation by binding to RAGEs [41, 42]. Studies in diabetic rodents treated with SGLT2i showed suppression of the AGE-RAGE axis in the kidney [43] and aortic tissues [44] but not in the myocardium [45].

\section{Natriuresis, diuresis, and reduction in plasma volume}

SGLT2i reduce the reabsorption of filtered glucose and sodium by blocking SGLT2, thus leading to natriuresis and osmotic diuresis. The natriuretic effect of SGLT2i may also be enhanced because of functional coordination with $\mathrm{Na}^{+} / \mathrm{H}^{+}$exchanger 3, which mediates a large fraction of sodium absorption in the proximal tubule [46]. Skin sodium levels, which are closely associated with left ventricular mass [47], are increased in patients with T2DM [48] and SGLT2 inhibition reduced skin sodium levels (without osmotic activity) in T2DM patients [49].

SGLT2i lead to a rapid increase in urine volume (approximately $110-470 \mathrm{ml} /$ day), which settles at a new stable level over 12 weeks [50], with a persistent decline in plasma volume of about $7 \%$ by 12 weeks [51]. The gradual attenuation of the diuretic effect is presumably regulated by compensatory mechanisms. A study in rats showed an increase in vasopressin-induced solute-free water reabsorption after administration of SGLT2i [52]. SGLT2i increase the sodium concentration delivered to 
the macula densa and thus enhance renal tubuloglomerular feedback signals, resulting in a decrease in GFR and contraction of the renal afferent arterioles [53].

SGLT2i attenuate congestion, with little effect on arterial perfusion, in patients with HF. A mathematical model suggested that this is because the osmotic diuresis induced by SGLT2i leads to greater clearance of electrolyte-free water in the intercellular space than in the blood vessels, causing a greater reduction in intercellular fluid volume, relative to circulating volume [54]. The improved quality of life in patients with HF during therapy with SGLT2i might be partly explained by this mechanism.

\section{Reduction in blood pressure}

Recent meta-analyses of clinical research that monitored ambulatory blood pressure show that SGLT2i therapy leads to a decline in systolic and diastolic blood pressure (approximately $3-4 \mathrm{mmHg}$ and $1-2 \mathrm{mmHg}$, respectively), over study durations of 4-12 weeks. The decrease in blood pressure is greater during the daytime than during the night $[55,56]$, and the effect does not vanish with more prolonged therapy $[15,16,57]$. The combined effects of SGLT2i on osmotic diuresis and natriuresis are postulated to play a major role in blood pressure lowering [53], although the effect of SGLT2i on the sympathetic nervous system may also contribute to the reduction in blood pressure [58]. Interestingly, the antihypertensive effect remains unchanged regardless of the dose of SGLT2i [55], also indicating little correlation between the dose and the cardiovascular benefits of SGLT2i, as mentioned above. The effect of SGLT2i on blood pressure may also be independent of renal function and glycemic control $[59,60]$.

Although SGLT2i reduce plasma volume and blood pressure, heart rate is not increased [18, 61, 62], probably implying that SGLT2i decrease the preload and afterload, with cardiac output maintained, or inhibit sympathetic nervous activity.

\section{Amelioration of endothelial dysfunction and vascular stiffness}

Arterial stiffness is strongly associated with hypertension, cardiovascular events, HF, and death [63-65], and endothelial dysfunction plays a vital role in the development of coronary artery disease and HF [66, 67]. Many clinical studies $[62,68-70]$ have shown that short-term therapy with SGLT2i mitigates aortic stiffness and improves endothelial function. One study [71], however, did not show such benefits, presumably because of differences in design and settings between this and the other studies. A study investigating the effects of long-term treatment is in progress and should further confirm the vascular benefits [72].

\section{Weight loss and effects on fat}

A systematic review of clinical research comparing SGLT2i monotherapy with placebo showed a treatmentrelated weight loss of approximately $1.5-3 \mathrm{~kg}$ [73]. A rapid decrease in body weight was observed during the initial few weeks, followed by a gentle decrease. Weight loss plateaued after 24 weeks and thereafter remained stable [74, 75]. Studies using bioimpedance spectroscopy showed that the weight loss during treatment with SGLT2i could be principally attributed to a decrease in both visceral and subcutaneous adipose tissue $[74,76$, $77]$, with no obvious change in lean tissue mass $[78,79]$. This finding is in line with other studies calculating adipose distribution indices $[80,81]$ or using $\mathrm{x}$-ray absorptiometry $[74,82]$. The initial rapid weight loss may be caused by a transient decrease of extracellular water (approximately $-0.5 \mathrm{~L}$ of extracellular fluid at 1 month), which gradually normalizes over the next few months $[78,83]$. It has been suggested that the reduction in adipose tissue mass after medication with SGLT2i may be caused by an energy loss (around 200-300 kilocalories per day $[84,85])$ due to increased glucose excretion [86, 87] and enhanced lipid mobilization [77, 88].

It is noteworthy that the decrease in epicardial adipose tissue mass observed with SGLT2i $[89,90]$ is independent of the antihyperglycemic effects [91]. In addition to reducing adipose tissue mass, SGLT2i attenuate systemic and adipose inflammation [77]. The accumulation and inflammation of epicardial fat may promote inflammation and fibrosis in the underlying tissues, thereby contributing to atrial tachyarrhythmias, ASCVD, and HF with preserved ejection fraction (HFpEF) [92]. SGLT2i probably generate cardiovascular benefits by blocking these pathogenic mechanisms.

\section{Protection of renal function}

The renal outcome trials of SGLT2i in patients with CKD have shown renal benefits, including preservation of eGFR and a reduction in albuminuria, although a rapid but slight decrease in eGFR was observed during the first month. The renal benefits and cardiovascular benefits were intertwined [17, 20]. Renal dysfunction is related to cardiac remodeling and systolic dysfunction in patients with HFpEF [93]. Cardiac and renal dysfunction are closely linked and partially share pathophysiological mechanisms [94].

\section{Improvement of cardiac energy metabolism}

During the development of HF, the substrate utilized by cardiomyocytes switches from free fatty acids towards glucose. Oxidation of fatty acids produces many adenosine triphosphate (ATP) molecules and has a high demand for oxygen molecules, whereas oxidation of 
glucose produces less ATP but has higher oxygen efficiency $[95,96]$. The switch from free fatty acids to glucose results in an energy deficiency [88], which lowers cardiac work efficiency and worsens HF. In addition to free fatty acids and glucose, $\beta$-hydroxybutyrate (a type of ketone body), which is most easily extracted by the myocardium [97], is also utilized by the heart in the fasting state. Oxidation of $\beta$-hydroxybutyrate has the highest oxygen efficiency and produces many ATP molecules with the lowest oxygen demand $[95,96]$. SGLT2i-induced glycosuria reduces blood glucose and consequently contributes to many metabolic adaptations similar to those in the fasting state, including decreased glucose oxidation, acceleration of lipolysis, augmentation of fat oxidation, and increased plasma concentrations of ketone bodies [88, 98]. SGLT2 inhibition also leads to a myocardial metabolic shift away from glucose toward ketone bodies and free fatty acids. This shift enhances the generation of myocardial energy, thereby improving myocardial remodeling and left ventricular systolic function [99]. The energetic advantage provided by preferential ketone body utilization by cardiomyocytes probably underlies the cardiovascular benefits of SGLT2i, as described in the "thrifty substrate" hypothesis [95].

Clinical studies have shown a slight increase in hematocrit, probably driven by a reduction in plasma volume and a transient elevation in erythropoietin [51]. The increased hematocrit is expected to enhance oxygen delivery to tissues [100] and improve cardiac metabolism. Additionally, ketone bodies, especially $\beta$-hydroxybutyrate, can also attenuate systemic inflammation and oxidative stress by inhibiting the Nod-like receptor protein 3 (NLRP3) inflammasome $[101,102]$ and class I histone deacetylases [103], and by activating G-protein coupled receptor 109 and hydroxycarboxylic acid receptor 2 [104]. Because plasma ketone levels are modestly elevated by SGLT2i $[88,105]$, the elevation in levels of ketone body exerts salutary effects with little increase in the occurrence of diabetic ketoacidosis $[18,19,22]$.

\section{Inhibition of cardiac $\mathrm{Na}^{+} / \mathrm{H}^{+}$exchanger}

Enhanced cardiac $\mathrm{Na}^{+} / \mathrm{H}^{+}$exchanger activity is found during the development of HF $[106,107]$. Studies in animal models demonstrate that SGLT2i lower cytoplasmic sodium and calcium concentrations and elevate mitochondrial calcium concentration via direct inhibition of the myocardial $\mathrm{Na}^{+} / \mathrm{H}^{+}$exchanger $[108,109]$. Previous animal studies showed that inhibition of the $\mathrm{Na}^{+} /$ $\mathrm{H}^{+}$exchanger alleviates myocardial hypertrophy and $\mathrm{HF}$ $[110,111]$, and that enhancing mitochondrial calcium concentrations during the development of HF is associated with attenuation of cardiac remodeling and fibrosis and the prevention of sudden cardiac death [112].
Inhibition of the $\mathrm{Na}^{+} / \mathrm{H}^{+}$exchanger may thus, to some extent, account for the cardiovascular benefits of SGLT2i.

Based on the inhibitory effect of SGLT2i on the $\mathrm{Na}^{+} /$ $\mathrm{H}^{+}$exchanger, a sodium hypothesis has been put forward. The reduction in mitochondrial calcium concentration, which is secondary to the elevation in intracellular sodium concentration in the failing myocardium, decreases the activity of Krebs cycle dehydrogenases, thus hindering regeneration of the reducing equivalents that plays a key role in matching energy supply to demand. Inhibition of the cardiac $\mathrm{Na}^{+} / \mathrm{H}^{+}$ exchanger by SGLT2i improves the failing myocardium by correcting sodium and calcium handling [113]. The sodium hypothesis is an extension of the "thrifty substrate" hypothesis [95].

\section{Reduction in serum uric acid level}

Uric acid, the end-product of purine metabolism in humans, is largely excreted in urine. SGLT2i-induced glycosuria competitively suppresses uric acid absorption by glucose transporter $9 \mathrm{~b}$ in the proximal tubule, leading to increased uric acid excretion and reduced plasma levels of uric acid [114, 115]. In a meta-analysis of 62 clinical studies involving 34,391 patients with T2DM, SGLT2i decreased plasma uric acid levels by $15-45 \mu \mathrm{mol} / \mathrm{L}$. The effect had a rapid onset and persisted during long-term treatment [116]. Increased uric acid stimulates the proliferation and hypertrophy of vascular smooth muscle cells [117], promotes intracellular oxidative stress [118], depletes nitric oxide [119], activates the vascular reninangiotensin system [120], and induces an inflammatory reaction [121]. Increased uric acid is also associated with hypertension [122], atrial fibrillation [123], and HF [124].

\section{Improvements in cardiac structure and function}

Since there is no expression of SGLT2 in the human heart [125], the underlying effect of SGLT2i on cardiac structure and function is probably mediated largely by hemodynamic, metabolic, and neurohormonal effects. In diabetic mice, SGLT2i reduces expression of pro-fibrotic proteins, decreases deposition of collagen I/III and $\alpha$-smooth muscle actin in the myocardial interstitium, and improves cardiomyocyte mitochondrial ultrastructure, thereby reducing cardiac fibrosis and hypertrophy, and improving diastolic function $[45,126]$. In rats with myocardial infarction, SGLT2i attenuate myocardial fibrosis by activating the signal transducer and activator of transcription 3 (STAT3) pathway and reducing the release of superoxide and nitrotyrosine [127]. In a nondiabetic pig model of HF, SGLT2 inhibition appears to improve cardiac remodeling at the three levels of anatomy, metabolism, and neurohormones, thereby enhancing cardiac systolic function [99]. 
Many clinical studies using cardiac magnetic resonance imaging or echocardiography have also shown that SGLT2i improve cardiac diastolic function and reduce left ventricular mass and volume [128-131]. However, most studies excluded individuals with overt HF and it, therefore, remains uncertain whether SGLT2i can attenuate advanced left ventricular remodeling.

\section{Attenuation of inflammation}

Low-grade inflammation is recognized to contribute to the development of atherosclerosis and to be associated with an increased risk of CVD [132, 133]. Many studies have indicated that SGLT2i slightly decrease circulating levels of inflammatory factors, including interleukin-6, high-sensitivity $\mathrm{C}$-reactive protein, and tumor necrosis factor- $\gamma$ and $-\alpha$, in patients with T2DM [90, 134-137]. SGLT2i also reduce M1 macrophage accumulation and polarize M2 macrophages in fat and liver [77]. The antiinflammatory effect of SGLT2i is probably mediated by many other factors, such as increased levels of ketone bodies and reduced levels of uric acid $[138,139]$.

\section{Other possible mechanisms}

Detection of increased luminal sodium concentrations by the macula densa would theoretically lower plasma renin levels by reducing the release of renin by juxtaglomerular cells, leading to inhibition of the renin-angiotensin-aldosterone system (RAAS). Animal studies showed that SGLT2i suppressed renal RAAS [140, 141] whereas a clinical study in outpatients with T2DM suggested that SGLT2i transiently enhanced plasma renin activity, which then returned to baseline after 3 months [78]. The effect of SGLT2i on the RAAS thus remains unclear.

A shift in cell life programs from defense to dormancy has been hypothesized to underlie the cardiovascular benefits of SGLT2i. The beneficial effects on the cardiovascular system are suggested to involve aspects of metabolism, hormones, and inflammation [142, 143] but this mechanism is not totally consistent with the "thrifty substrate" hypothesis.

\section{Prospects for use of SGLT2i in CVD}

Extensive clinical studies of SGLT2i consistently suggested an improvement in the quality of life and prognosis of individuals with HFrEF, including more advanced but stable HFrEF. A comparative analysis of three large randomized controlled trials also supports the combined use of an SGLT2i, a mineralocorticoid receptor antagonist, an angiotensin receptor-neprilysin inhibitor, and a $\beta$-blocker as a new treatment standard for HFrEF. This new therapeutic regimen produced greater treatment effects than traditional therapy with an angiotensin-converting enzyme inhibitor or angiotensin receptor blocker and $\beta$-blocker [144]. In the future, SGLT2i have great potential to be a preferred class of cardiovascular drugs to treat HFrEF.

Almost half of patients with HF have HFpEF [145]. In observational studies, patients with HFpEF have a similar incidence of hospitalization and death to patients with HFrEF, but have better outcomes [146]. Several hemodynamic and molecular mechanisms, such as left atrial hypertension, increased circulating volume, microvascular inflammation, cardiometabolic dysfunction, and cardiac fibrosis, have been suggested to offer potential treatment opportunities for HFpEF [147]. As discussed above, many experimental and clinical studies have shown that SGLT2i have a beneficial role in these aspects of disease, though the subjects in most studies did not have HFpEF. SGLT2i improved left ventricular remodeling and diastolic function in animal models with HFpEF and in cardiac tissues from patients with HFpEF [148, 149]. The SOLOIST-WHF trial demonstrated that sotagliflozin significantly reduced the composite risk of hospitalization or urgent visit for HF or death from cardiovascular causes in patients with HFpEF [25]. Whether other SGLT2i likewise have cardiovascular benefits in patients with HFpEF remains unknown.

The DECLARE-TIMI 58 trial and the VERTIS-CV trial did not show significant improvement in cardiovascular outcomes (except for hospitalization for HF) in patients with established ASCVD or risk factors for ASCVD [22, 24]. Other large clinical studies of SGLT2i also showed no marked reduction in the occurrence of ASCVD, including myocardial infarction and stroke. Consequently, SGLT2i may only have a modest benefit in the treatment of ASCVD.

SGLT2i share many pharmacological advantages, including rapid oral absorption, long half-life, absence of clinically relevant drug-drug interactions, extensive hepatic biotransformation, and low renal clearance of the parent drug [150]. Practice guidelines have recommended using SGLT2i in patients with T2DM and CVD or CKD because of the proven cardiorenal benefits [151, 152].

Of note, recent large-scale clinical trials have likewise revealed substantial cardiorenal benefits in patients without T2DM (Fig. 3). The EMPEROR-Reduced trial [15] and the DAPA-HF trial [16] both showed a remarkable reduction in risk of hospitalization for HF or death from cardiovascular causes in nondiabetic patients with HFrEF after treatment with SGLT2i. The DAPA-CKD trial [17] demonstrated renal protection in nondiabetic patients with CKD. These results signify that the therapeutic spectrum of SGLT2i will probably be extended to nondiabetic individuals with HFrEF or CKD. 


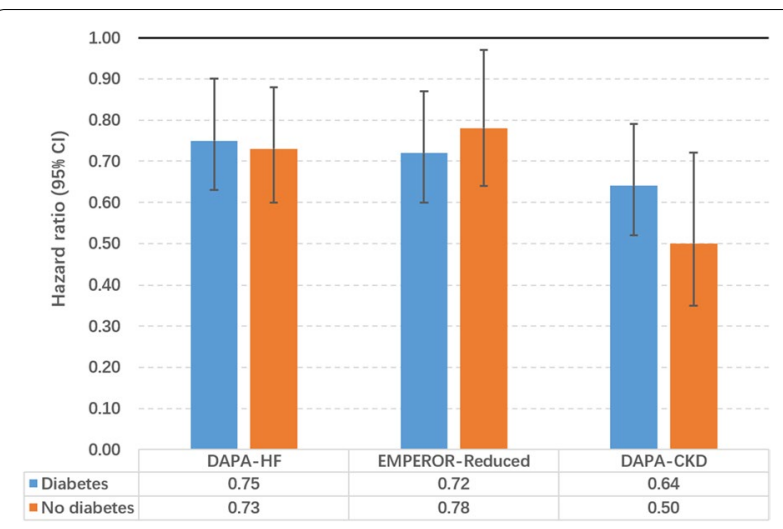

Fig. 3 Primary cardiorenal outcomes in diabetic and nondiabetic patients in three large-scale clinical trials. The primary outcome of the DAPA-HF trial is a composite of hospitalization or urgent visit with intravenous therapy for heart failure or death from cardiovascular causes. The primary outcome of the EMPEROR-Reduced trial is a composite of hospitalization for heart failure or death from cardiovascular causes. The primary outcome of the DAPA-CKD trial is a composite of end-stage kidney disease, sustained decline of $50 \%$ in eGFR, or renal or cardiovascular death. Cardiorenal protection is seen consistently in patients with or without diabetes. $\mathrm{Cl}$, confidence interval

\section{Conclusions}

Large-scale clinical trials of SGLT2i all showed cardiovascular benefits across different patients, most notably a significant decrease in the occurrence of HF. Because of the proven benefits of SGLT2i, which are independent of glycemic control, many international guidelines recommend the use of SGLT2i in diabetic patients with CVD. SGLT2i directly increase natriuresis and glycosuria, leading to a spectrum of downstream effects. These effects jointly underlie the cardiovascular benefits of SGLT2i. Recently, several large-scale trials have discovered similar cardiovascular benefits in nondiabetic patients with HFrEF. Consequently, SGLT2i will be likely to be used to treat nondiabetic patients with HFrEF.

\section{Abbreviations}

AGE: Advanced glycation end product; ASCVD: Atherosclerotic cardiovascular diseases; ATP: Adenosine triphosphate; CANVAS: Canagliflozin Cardiovascular Assessment Study; CREDENCE: Canagliflozin and Renal Events in Diabetes with Established Nephropathy Clinical Evaluation; CVD: Cardiovascular diseases; DAPA-CKD: Dapagliflozin and Prevention of Adverse Outcomes in Chronic Kidney Disease: DAPA-HF: Dapagliflozin and Prevention of Adverse Outcomes in Heart Failure; DECLARE-TIMI 58: Dapagliflozin Effect on Cardiovascular EventsThrombolysis in Myocardial Infarction 58; eGFR: Estimated glomerular filtration rate; EMA: European Medicines Agency; EMPA-REG OUTCOME: Empagliflozin Cardiovascular Outcome Event Trial in Type 2 Diabetes Mellitus Patients; PEROR-Reduced: Empagliflozin Outcome Trial in Patients with Chronic Heart Failure and a Reduced Ejection Fraction; FDA: Food and Drug Administration; HbA1c: Glycosylated hemoglobin; HF: Heart failure; HFpEF: Heart failure with preserved ejection fraction; HFrEF: Heart failure with reduced ejection fraction; KCCQ: Kansas City Cardiomyopathy Questionnaire; MACE: Major adverse cardiovascular events, including death from cardiovascular causes, non-fatal myocardial infarction, and non-fatal stroke; NLRP3: Nod-like receptor protein 3;
}

RAAS: Renin-angiotensin-aldosterone system; RAGE: Receptor for advanced glycation end products; SGLT2i: Sodium-glucose cotransporter 2 inhibitors; SOLOIST-WHF: Effect of Sotagliflozin on Cardiovascular Events in Patients with Type 2 Diabetes Post Worsening Heart Failure; STAT3: Signal transducer and activator of transcription 3;T1DM:Type 1 diabetes mellitus; T2DM: Type 2 diabetes mellitus; VERTIS-CV: Evaluation of Ertugliflozin Efficacy and Safety Cardiovascular Outcomes.

\section{Acknowledgements}

Not applicable.

\section{Authors' contributions}

$B X$ and $X Z$ wrote the manuscript; $X Z$ revised the manuscript. All authors read and approved the final manuscript.

\section{Funding}

This work was funded by the Talent Support Project of the Second Affiliated Hospital of Soochow University (XKTJ-RC202003).

\section{Availability of data and materials}

Not applicable.

\section{Declarations}

Ethics approval and consent to participate

Not applicable.

\section{Consent for publication}

Not applicable.

\section{Competing interests}

The authors declare that they have no competing interests.

Received: 5 February 2021 Accepted: 19 March 2021

Published online: 07 April 2021

\section{References}

1. Marsenic O. Glucose control by the kidney: an emerging target in diabetes. Am J Kidney Dis. 2009;53(5):875-83.

2. Crane RK. The restrictions on possible mechanisms of intestinal transport of sugars. Membrane Transport and Metabolism. In: Proceedings of a symposium held in Prague, August 22-27, 1960. 1961. pp 439-449.

3. Wright EM, Loo DD, Hirayama BA, Turk E. Surprising versatility of Na+glucose cotransporters: SLC5. Physiology (Bethesda). 2004:19:370-6.

4. Liu JJ, Lee T, DeFronzo RA. Why Do SGLT2 inhibitors inhibit only $30-50 \%$ of renal glucose reabsorption in humans? Diabetes. 2012;61(9):2199-204.

5. Bakris GL, Fonseca VA, Sharma K, Wright EM. Renal sodium-glucose transport: role in diabetes mellitus and potential clinical implications. Kidney Int. 2009;75(12):1272-7.

6. Himsworth HP. The relation of glycosuria to glycaemia and the determination of the renal threshold for glucose. Biochem J. 1931;25(4):1128-46.

7. Wright EM, Loo DD, Hirayama BA. Biology of human sodium glucose transporters. Physiol Rev. 2011;91(2):733-94.

8. Rieg T, Masuda T, Gerasimova M, Mayoux E, et al. Increase in SGLT1mediated transport explains renal glucose reabsorption during genetic and pharmacological SGLT2 inhibition in euglycemia. Am J Physiol Renal Physiol. 2014;306(2):F188-93.

9. List JF, Woo V, Morales E, Tang W, et al. Sodium-glucose cotransport inhibition with dapagliflozin in type 2 diabetes. Diabetes Care. 2009;32(4):650-7.

10. Komoroski B, Vachharajani N, Feng Y, Li L, et al. Dapagliflozin, a novel, selective SGLT2 inhibitor, improved glycemic control over 2 weeks in patients with type 2 diabetes mellitus. Clin Pharmacol Ther. 2009;85(5):513-9. 
11. Holman RR, Paul SK, Bethel MA, Matthews DR, et al. 10-year followup of intensive glucose control in type 2 diabetes. N Engl J Med. 2008;359(15):1577-89.

12. Hayward RA, Reaven PD, Wiitala WL, Bahn GD, et al. Follow-up of glycemic control and cardiovascular outcomes in type 2 diabetes. N Engl J Med. 2015;372(23):2197-206.

13. Inzucchi SE, Zinman B, Fitchett D, Wanner C, et al. How does empagliflozin reduce cardiovascular mortality? insights from a mediation analysis of the EMPA-REG OUTCOME trial. Diabetes Care. 2018:41(2):356-63.

14. Inzucchi SE, Kosiborod M, Fitchett D, Wanner C, et al. Improvement in cardiovascular outcomes with empagliflozin is independent of glycemic control. Circulation. 2018;138(17):1904-7.

15. Packer M, Anker SD, Butler J, Filippatos G, et al. Cardiovascular and renal outcomes with empagliflozin in heart failure. N Engl J Med. 2020;383(15):1413-24.

16. McMurray JJV, Solomon SD, Inzucchi SE, Køber L, et al. Dapagliflozin in patients with heart failure and reduced ejection fraction. N Engl J Med. 2019;381(21):1995-2008.

17. Heerspink HJL, Stefánsson BV, Correa-Rotter R, Chertow GM, et al. Dapagliflozin in patients with chronic kidney disease. N Engl J Med. 2020;383(15):1436-46

18. Zinman B, Wanner C, Lachin JM, Fitchett D, et al. Empagliflozin, cardiovascular outcomes, and mortality in type 2 diabetes. N Engl J Med. 2015:373(22):2117-28.

19. Neal B, Perkovic V, Mahaffey KW, de Zeeuw D, et al. Canagliflozin and cardiovascular and renal events in type 2 diabetes. N Engl J Med. 2017:377(7):644-57.

20. Perkovic V, Jardine MJ, Neal B, Bompoint S, et al. Canagliflozin and renal outcomes in type 2 diabetes and nephropathy. $\mathrm{N}$ Engl J Med. 2019;380(24):2295-306.

21. Cannon CP, Perkovic V, Agarwal R, Baldassarre J, et al. Evaluating the effects of canagliflozin on cardiovascular and renal events in patients with type 2 diabetes mellitus and chronic kidney disease according to baseline $\mathrm{HbA} 1 \mathrm{c}$, including those with $\mathrm{HbA} 1 \mathrm{c}<7 \%$ : results from the CREDENCE trial. Circulation. 2020;141(5):407-10.

22. Wiviott SD, Raz I, Bonaca MP, Mosenzon O, et al. Dapagliflozin and cardiovascular outcomes in type 2 diabetes. N Engl J Med. 2019:380(4):347-57.

23. Zelniker TA, Morrow DA, Mosenzon O, Goodrich EL, et al. Relationship between baseline cardiac biomarkers and cardiovascular death or hospitalization for heart failure with and without SGLT2 inhibitor therapy in DECLARE-TIMI 58. Eur J Heart Fail. 2020. https://doi.org/10.1002/ejhf. 2073

24. Cannon CP, Pratley R, Dagogo-Jack S, Mancuso J, et al. Cardiovascular outcomes with ertugliflozin in type 2 diabetes. N Engl J Med. 2020;383(15):1425-35

25. Bhatt DL, Szarek M, Steg PG, Cannon CP, et al. Sotagliflozin in patients with diabetes and recent worsening heart failure. N Engl J Med. 2021;384(2):117-28

26. Liakos A, Karagiannis T, Athanasiadou E, Sarigianni M, et al. Efficacy and safety of empagliflozin for type 2 diabetes: a systematic review and meta-analysis. Diabetes Obes Metab. 2014;16(10):984-93.

27. Vasilakou D, Karagiannis T, Athanasiadou E, Mainou M, et al. Sodiumglucose cotransporter 2 inhibitors for type 2 diabetes: a systematic review and meta-analysis. Ann Intern Med. 2013;159(4):262-74.

28. Fujita $Y$, Inagaki N. Renal sodium glucose cotransporter 2 inhibitors as a novel therapeutic approach to treatment of type 2 diabetes: clinical data and mechanism of action. J Diabetes Investig. 2014;5(3):265-75.

29. Yamada T, Shojima N, Noma H, Yamauchi T, et al. Sodium-glucose cotransporter-2 inhibitors as add-on therapy to insulin for type 1 diabetes mellitus: systematic review and meta-analysis of randomized controlled trials. Diabetes Obes Metab. 2018;20(7):1755-61.

30. El Masri D, Ghosh S, Jaber LA. Safety and efficacy of sodium-glucose cotransporter 2 (SGLT2) inhibitors in type 1 diabetes: A systematic review and meta-analysis. Diabetes Res Clin Pract. 2018;137:83-92.

31. Barnett AH, Mithal $A$, Manassie J, Jones R, et al. Efficacy and safety of empagliflozin added to existing antidiabetes treatment in patients with type 2 diabetes and chronic kidney disease: a randomised, double-blind, placebo-controlled trial. Lancet Diabetes Endocrinol. 2014;2(5):369-84.
32. Fitchett D. A safety update on sodium glucose co-transporter 2 inhibitors. Diabetes Obes Metab. 2019;21(Suppl 2):34-42.

33. Kohler S, Zeller C, Iliev H, Kaspers S. Safety and tolerability of empagliflozin in patients with type 2 diabetes: pooled analysis of phase I-III clinical trials. Adv Ther. 2017;34(7):1707-26.

34. Thorpe SR, Baynes JW. Maillard reaction products in tissue proteins: new products and new perspectives. Amino Acids. 2003;25(3-4):275-81.

35. Brett J, Schmidt AM, Yan SD, Zou YS, et al. Survey of the distribution of a newly characterized receptor for advanced glycation end products in tissues. Am J Pathol. 1993;143(6):1699-712.

36. Deluyker D, Evens L, Bito V. Advanced glycation end products (AGEs) and cardiovascular dysfunction: focus on high molecular weight AGEs. Amino Acids. 2017:49(9):1535-41.

37. Hegab Z, Gibbons S, Neyses L, Mamas MA. Role of advanced glycation end products in cardiovascular disease. World J Cardiol. 2012:4(4):90-102

38. Zieman SJ, Kass DA. Advanced glycation endproduct crosslinking in the cardiovascular system: potential therapeutic target for cardiovascular disease. Drugs. 2004;64(5):459-70.

39. Corman B, Duriez M, Poitevin P, Heudes D, et al. Aminoguanidine prevents age-related arterial stiffening and cardiac hypertrophy. Proc Natl Acad Sci USA. 1998;95(3):1301-6.

40. Candido R, Forbes JM, Thomas MC, Thallas V, et al. A breaker of advanced glycation end products attenuates diabetes-induced myocardial structural changes. Circ Res. 2003;92(7):785-92.

41. Yan SD, Schmidt AM, Anderson GM, Zhang J, et al. Enhanced cellular oxidant stress by the interaction of advanced glycation end products with their receptors/binding proteins. J Biol Chem. 1994;269(13):9889-97.

42. Basta G, Schmidt AM, De Caterina R. Advanced glycation end products and vascular inflammation: implications for accelerated atherosclerosis in diabetes. Cardiovasc Res. 2004;63(4):582-92.

43. Ojima A, Matsui T, Nishino Y, Nakamura N, et al. Empagliflozin, an inhibitor of sodium-glucose cotransporter 2 exerts anti-inflammatory and antifibrotic effects on experimental diabetic nephropathy partly by suppressing AGEs-receptor axis. Horm Metab Res. 2015;47(9):686-92.

44. Oelze M, Kröller-Schön S, Welschof P, Jansen T, et al. The sodiumglucose co-transporter 2 inhibitor empagliflozin improves diabetesinduced vascular dysfunction in the streptozotocin diabetes rat model by interfering with oxidative stress and glucotoxicity. PLoS ONE. 2014;9(11):e112394.

45. Habibi J, Aroor AR, Sowers JR, Jia G, et al. Sodium glucose transporter 2 (SGLT2) inhibition with empagliflozin improves cardiac diastolic function in a female rodent model of diabetes. Cardiovasc Diabetol. 2017;16(1):9.

46. Silva Dos Santos D, Polidoro JZ, Borges-Júnior FA, Girardi ACC Cardioprotection conferred by sodium-glucose cotransporter 2 inhibitors: a renal proximal tubule perspective. Am J Physiol Cell Physiol. 2020:318(2):328-36.

47. Schneider MP, Raff U, Kopp C, Scheppach JB, et al. Skin sodium concentration correlates with left ventricular hypertrophy in CKD. J Am Soc Nephrol. 2017;28(6):1867-76.

48. Kopp C, Linz P, Maier C, Wabel P, et al. Elevated tissue sodium deposition in patients with type 2 diabetes on hemodialysis detected by (23) Na magnetic resonance imaging. Kidney Int. 2018;93(5):1191-7.

49. Karg MV, Bosch A, Kannenkeril D, Striepe K, et al. SGLT-2-inhibition with dapagliflozin reduces tissue sodium content: a randomised controlled trial. Cardiovasc Diabetol. 2018;17(1):5.

50. Tanaka H, Takano K, lijima H, Kubo H, et al. Factors affecting canagliflozin-induced transient urine volume increase in patients with type 2 diabetes mellitus. Adv Ther. 2017;34(2):436-51.

51. Lambers Heerspink HJ, de Zeeuw D, Wie L, Leslie B, et al. Dapagliflozin a glucose-regulating drug with diuretic properties in subjects with type 2 diabetes. Diabetes Obes Metab. 2013;15(9):853-62.

52. Masuda T, Muto S, Fukuda K, Watanabe M, et al. Osmotic diuresis by SGLT2 inhibition stimulates vasopressin-induced water reabsorption to maintain body fluid volume. Physiol Rep. 2020;8(2):e14360.

53. Sarzani R, Giulietti F, Di Pentima C, Spannella F. Sodium-glucose cotransporter-2 inhibitors: peculiar "hybrid" diuretics that protect from target organ damage and cardiovascular events. Nutr Metab Cardiovasc Dis. 2020:30(10):1622-32. 
54. Hallow KM, Helmlinger G, Greasley PJ, McMurray JJV, et al. Why do SGLT2 inhibitors reduce heart failure hospitalization? A differential volume regulation hypothesis. Diabetes Obes Metab. 2018;20(3):479-87.

55. Georgianos PI, Agarwal R. Ambulatory blood pressure reduction with SGLT-2 inhibitors: dose-response meta-analysis and comparative evaluation with low-dose hydrochlorothiazide. Diabetes Care. 2019:42(4):693-700

56. Baker WL, Buckley LF, Kelly MS, Bucheit JD, et al. Effects of sodiumglucose cotransporter 2 inhibitors on 24-hour ambulatory blood pressure: a systematic review and meta-analysis. J Am Heart Assoc. 2017;6(5):e005686.

57. Mazidi M, Rezaie P, Gao HK, Kengne AP. Effect of sodium-glucose cotransport-2 inhibitors on blood pressure in people with type 2 diabetes mellitus: a systematic review and meta-analysis of 43 randomized control trials with 22528 patients. J Am Heart Assoc. 2017;6(6):e004007.

58. Wan N, Rahman A, Hitomi H, Nishiyama A. The effects of sodium-glucose cotransporter 2 inhibitors on sympathetic nervous activity. Front Endocrinol (Lausanne). 2018;9:421.

59. Jones B. Chronic kidney disease: empagliflozin-one step closer to glycaemic control in patients with type II diabetes and CKD? Nat Rev Nephrol. 2014;10(4):181.

60. Kohan DE, Fioretto P, Tang W, List JF. Long-term study of patients with type 2 diabetes and moderate renal impairment shows that dapagliflozin reduces weight and blood pressure but does not improve glycemic control. Kidney Int. 2014;85(4):962-71.

61. Storgaard H, Gluud LL, Bennett C, Grøndahl MF, et al. Benefits and harms of sodium-glucose co-transporter 2 inhibitors in patients with type 2 diabetes: a systematic review and meta-analysis. PLOS ONE. 2016;11(11):e0166125.

62. Chilton R, Tikkanen I, Cannon CP, Crowe S, et al. Effects of empagliflozin on blood pressure and markers of arterial stiffness and vascular resistance in patients with type 2 diabetes. Diabetes Obes Metab. 2015;17(12):1180-93.

63. Vlachopoulos C, Aznaouridis K, Stefanadis C. Prediction of cardiovascular events and all-cause mortality with arterial stiffness: a systematic review and meta-analysis. J Am Coll Cardiol. 2010;55(13):1318-27.

64. Chow B, Rabkin SW. The relationship between arterial stiffness and heart failure with preserved ejection fraction: a systemic meta-analysis. Heart Fail Rev. 2015;20(3):291-303.

65. Safar ME. Arterial stiffness as a risk factor for clinical hypertension. Nat Rev Cardiol. 2018;15(2):97-105.

66. Marti CN, Gheorghiade M, Kalogeropoulos AP, Georgiopoulou V, et al. Endothelial dysfunction, arterial stiffness, and heart failure. J Am Coll Cardiol. 2012;60(16):1455-69.

67. Gutiérrez E, Flammer AJ, Lerman LO, Elízaga J, et al. Endothelial dysfunction over the course of coronary artery disease. Eur Heart J. 2013;34(41):3175-81.

68. Striepe K, Jumar A, Ott C, Karg MV, et al. Effects of the selective sodiumglucose cotransporter 2 inhibitor empagliflozin on vascular function and central hemodynamics in patients with type 2 diabetes mellitus. Circulation. 2017:136(12):1167-9.

69. Ott C, Jumar A, Striepe K, Friedrich S, et al. A randomised study of the impact of the SGLT2 inhibitor dapagliflozin on microvascular and macrovascular circulation. Cardiovasc Diabetol. 2017;16(1):26.

70. Solini A, Giannini L, Seghieri M, Vitolo E, et al. Dapagliflozin acutely improves endothelial dysfunction, reduces aortic stiffness and renal resistive index in type 2 diabetic patients: a pilot study. Cardiovasc Diabetol. 2017;16(1):138.

71. Tanaka A, Shimabukuro M, Machii N, Teragawa H, et al. Effect of empagliflozin on endothelial function in patients with type 2 diabetes and cardiovascular disease: results from the multicenter, randomized, placebo-controlled Double-Blind EMBLEM Trial. Diabetes Care. 2019;42(10):e159-61.

72. Tanaka A, Murohara T, Taguchi I, Eguchi K, et al. Rationale and design of a multicenter randomized controlled study to evaluate the preventive effect of ipragliflozin on carotid atherosclerosis: the PROTECT study. Cardiovasc Diabetol. 2016;15(1):133.

73. Johnston R, Uthman O, Cummins E, Clar C, et al. Canagliflozin, dapagliflozin and empagliflozin monotherapy for treating type 2 diabetes: systematic review and economic evaluation. Health Technol Assess. 2017:21(2):1-218
74. Bolinder J, Ljunggren O, Kullberg J, Johansson L, et al. Effects of dapagliflozin on body weight, total fat mass, and regional adipose tissue distribution in patients with type 2 diabetes mellitus with inadequate glycemic control on metformin. J Clin Endocrinol Metab. 2012;97(3):1020-31.

75. Bolinder J, Ljunggren Ö, Johansson L, Wilding J, et al. Dapagliflozin maintains glycaemic control while reducing weight and body fat mass over 2 years in patients with type 2 diabetes mellitus inadequately controlled on metformin. Diabetes Obes Metab. 2014;16(2):159-69.

76. Cefalu WT, Leiter LA, Yoon KH, Arias P, et al. Efficacy and safety of canagliflozin versus glimepiride in patients with type 2 diabetes inadequately controlled with metformin (CANTATA-SU): 52 week results from a randomised, double-blind, phase 3 non-inferiority trial. Lancet. 2013;382(9896):941-50.

77. Xu L, Nagata N, Nagashimada M, Fen ZG, et al. SGLT2 inhibition by empagliflozin promotes fat utilization and browning and attenuates inflammation and insulin resistance by polarizing M2 macrophages in diet-induced obese mice. EBioMedicine. 2017;20:137-49.

78. Schork A, Saynisch J, Vosseler A, Jaghutriz BA, et al. Effect of SGLT2 inhibitors on body composition, fluid status and renin-angiotensinaldosterone system in type 2 diabetes: a prospective study using bioimpedance spectroscopy. Cardiovasc Diabetol. 2019;18(1):46.

79. Blonde L, Stenlöf K, Fung A, Xie J, et al. Effects of canagliflozin on body weight and body composition in patients with type 2 diabetes over 104 weeks. Postgrad Med. 2016;128(4):371-80.

80. Neeland IJ, McGuire DK, Chilton R, Crowe S, et al. Empagliflozin reduces body weight and indices of adipose distribution in patients with type 2 diabetes mellitus. Diab Vasc Dis Res. 2016;13(2):119-26.

81. Neeland IJ, McGuire DK, Eliasson B, Ridderstråle M, et al. Comparison of adipose distribution indices with gold standard body composition assessments in the EMPA-REG H2H SU trial: a body composition substudy. Diabetes Ther. 2015;6(4):635-42.

82. Inoue H, Morino K, Ugi S, Tanaka-Mizuno S, et al. Ipragliflozin, a sodium-glucose cotransporter 2 inhibitor, reduces bodyweight and fat mass, but not muscle mass, in Japanese type 2 diabetes patients treated with insulin: a randomized clinical trial. J Diabetes Investig. 2019;10(4):1012-21.

83. Schwaiger E, Burghart L, Signorini L, Ristl R, et al. Empagliflozin in posttransplantation diabetes mellitus: a prospective, interventional pilot study on glucose metabolism, fluid volume, and patient safety. Am J Transplant. 2019;19(3):907-19.

84. Ferrannini G, Hach T, Crowe S, Sanghvi A, et al. Energy Balance after sodium-glucose cotransporter 2 inhibition. Diabetes Care. 2015;38(9):1730-5.

85. Rajeev SP, Cuthbertson DJ, Wilding JPH. Energy balance and metabolic changes with sodium-glucose co-transporter 2 inhibition. Diabetes Obes Metab. 2016;18(2):125-34.

86. Lee PC, Ganguly S, Goh SY. Weight loss associated with sodium-glucose cotransporter-2 inhibition: a review of evidence and underlying mechanisms. Obes Rev. 2018;19(12):1630-41.

87. Rajasekeran H, Lytvyn Y, Cherney DZ. Sodium-glucose cotransporter 2 inhibition and cardiovascular risk reduction in patients with type 2 diabetes: the emerging role of natriuresis. Kidney Int. 2016;89(3):524-6.

88. Ferrannini E, Baldi S, Frascerra S, Astiarraga B, et al. Shift to fatty substrate utilization in response to sodium-glucose cotransporter 2 inhibition in subjects without diabetes and patients with type 2 diabetes. Diabetes. 2016;65(5):1190-5.

89. Bouchi R, Terashima M, Sasahara Y, Asakawa M, et al. Luseogliflozin reduces epicardial fat accumulation in patients with type 2 diabetes: a pilot study. Cardiovasc Diabetol. 2017;16(1):32.

90. Sato T, Aizawa Y, Yuasa S, Kishi S, et al. The effect of dapagliflozin treatment on epicardial adipose tissue volume. Cardiovasc Diabetol. 2018;17(1):6.

91. Yagi $S$, Hirata Y, Ise T, Kusunose $K$, et al. Canagliflozin reduces epicardial fat in patients with type 2 diabetes mellitus. Diabetol Metab Syndr. 2017:9:78.

92. Packer M. Epicardial adipose tissue may mediate deleterious effects of obesity and inflammation on the myocardium. J Am Coll Cardiol. 2018;71(20):2360-72. 
93. Gori M, Senni M, Gupta DK, Charytan DM, et al. Association between renal function and cardiovascular structure and function in heart failure with preserved ejection fraction. Eur Heart J. 2014;35(48):3442-51.

94. Zannad F, Rossignol P. Cardiorenal syndrome revisited. Circulation. 2018;138(9):929-44.

95. Ferrannini E, Mark M, Mayoux E. CV protection in the EMPA-REG OUTCOME trial: a"Thrifty Substrate" hypothesis. Diabetes Care. 2016;39(7):1108-14.

96. Mudaliar S, Alloju S, Henry RR. Can a shift in fuel energetics explain the beneficial cardiorenal outcomes in the EMPA-REG OUTCOME study? A unifying hypothesis. Diabetes Care. 2016;39(7):1115-22.

97. Ferrannini E, Santoro D, Bonadonna R, Natali A, et al. Metabolic and hemodynamic effects of insulin on human hearts. Am J Physiol. 1993;264(2 Pt 1):E308-15.

98. Ferrannini E, Muscelli E, Frascerra S, Baldi S, et al. Metabolic response to sodium-glucose cotransporter 2 inhibition in type 2 diabetic patients. J Clin Invest. 2014;124(2):499-508.

99. Santos-Gallego CG, Requena-Ibanez JA, San Antonio R, Ishikawa K, et al. Empagliflozin ameliorates adverse left ventricular remodeling in nondiabetic heart failure by enhancing myocardial energetics. J Am Coll Cardiol. 2019;73(15):1931-44.

100. Testani JM, Chen J, McCauley BD, Kimmel SE, et al. Potential effects of aggressive decongestion during the treatment of decompensated heart failure on renal function and survival. Circulation. 2010;122(3):265-72

101. Youm YH, Nguyen KY, Grant RW, Goldberg EL, et al. The ketone metabolite $\beta$-hydroxybutyrate blocks NLRP3 inflammasome-mediated inflammatory disease. Nat Med. 2015;21(3):263-9.

102. Yamanashi T, Iwata M, Kamiya N, Tsunetomi K, et al. Beta-hydroxybutyrate, an endogenic NLRP3 inflammasome inhibitor, attenuates stress-induced behavioral and inflammatory responses. Sci Rep. 2017;7(1):7677.

103. Shimazu T, Hirschey MD, Newman J, He W, et al. Suppression of oxidative stress by $\beta$-hydroxybutyrate, an endogenous histone deacetylase inhibitor. Science. 2013:339(6116):211-4.

104. Rahman M, Muhammad S, Khan MA, Chen H, et al. The $\beta$-hydroxybutyrate receptor HCA2 activates a neuroprotective subset of macrophages. Nat Commun. 2014;5:3944.

105. Nishimura R, Tanaka Y, Koiwai K, Inoue K, et al. Effect of empagliflozin monotherapy on postprandial glucose and 24-hour glucose variability in Japanese patients with type 2 diabetes mellitus: a randomized, double-blind, placebo-controlled, 4-week study. Cardiovasc Diabetol. 2015;14:11.

106. Yokoyama H, Gunasegaram S, Harding SE, Avkiran M. Sarcolemmal $\mathrm{Na}+/ \mathrm{H}+$ exchanger activity and expression in human ventricular myocardium. J Am Coll Cardiol. 2000;36(2):534-40.

107. Hui Y, Junzhu C, Jianhua Z. Gap junction and Na+-H+ exchanger alternations in fibrillating and failing atrium. Int J Cardiol. 2008;128(1):147-9.

108. Baartscheer A, Schumacher CA, Wust RCI, Fiolet JWT, et al. Empagliflozin decreases myocardial cytoplasmic $\mathrm{Na}+$ through inhibition of the cardiac $\mathrm{Na}+/ \mathrm{H}+$ exchanger in rats and rabbits. Diabetologia. 2017;60(3):568-73.

109. Uthman L, Baartscheer A, Bleijlevens B, Schumacher CA, et al. Class effects of SGLT2 inhibitors in mouse cardiomyocytes and hearts: inhibition of $\mathrm{Na}+/ \mathrm{H}+$ exchanger, lowering of cytosolic $\mathrm{Na}+$ and vasodilation. Diabetologia. 2018;61(3):722-6.

110. Baartscheer A, Hardziyenka M, Schumacher CA, Belterman CN, et al. Chronic inhibition of the $\mathrm{Na}+/ \mathrm{H}+-$ exchanger causes regression of hypertrophy, heart failure, and ionic and electrophysiological remodelling. Br J Pharmacol. 2008;154(6):1266-75.

111. Baartscheer A, Schumacher CA, van Borren MM, Belterman CN, et al. Chronic inhibition of $\mathrm{Na}+/ \mathrm{H}+$-exchanger attenuates cardiac hypertrophy and prevents cellular remodeling in heart failure. Cardiovasc Res. 2005;65(1):83-92.

112. Liu T, Takimoto E, Dimaano VL, DeMazumder D, et al. Inhibiting mitochondrial $\mathrm{Na}+/ \mathrm{Ca} 2+$ exchange prevents sudden death in a Guinea pig model of heart failure. Circ Res. 2014;115(1):44-54.

113. Bertero E, Prates Roma L, Ameri P, Maack C. Cardiac effects of SGLT2 inhibitors: the sodium hypothesis. Cardiovasc Res. 2018;114(1):12-8.

114. Chino Y, Samukawa Y, Sakai S, Nakai Y, et al. SGLT2 inhibitor lowers serum uric acid through alteration of uric acid transport activity in renal tubule by increased glycosuria. Biopharm Drug Dispos. 2014;35(7):391-404.

115. Lytvyn Y, Škrtić M, Yang GK, Yip PM, et al. Glycosuria-mediated urinary uric acid excretion in patients with uncomplicated type 1 diabetes mellitus. Am J Physiol Renal Physiol. 2015;308(2):F77-83.

116. Zhao Y, Xu L, Tian D, Xia P, et al. Effects of sodium-glucose co-transporter 2 (SGLT2) inhibitors on serum uric acid level: A meta-analysis of randomized controlled trials. Diabetes Obes Metab. 2018;20(2):458-62.

117. Kırça M, Oğuz N, Cetin A, Uzuner F, et al. Uric acid stimulates proliferative pathways in vascular smooth muscle cells through the activation of p38 MAPK, p44/42 MAPK and PDGFRß. J Recept Signal Transduct Res. 2017;37(2):167-73.

118. Sautin YY, Johnson RJ. Uric acid: the oxidant-antioxidant paradox. Nucleosides Nucleotides Nucleic Acids. 2008;27(6):608-19.

119. Gersch C, Palii SP, Kim KM, Angerhofer A, et al. Inactivation of nitric oxide by uric acid. Nucleosides Nucleotides Nucleic Acids, 2008;27(8):967-78.

120. Corry DB, Eslami P, Yamamoto K, Nyby MD, et al. Uric acid stimulates vascular smooth muscle cell proliferation and oxidative stress via the vascular renin-angiotensin system. J Hypertens. 2008;26(2):269-75.

121. Gasse P, Riteau N, Charron S, Girre S, et al. Uric acid is a danger signal activating NALP3 inflammasome in lung injury inflammation and fibrosis. Am J Respir Crit Care Med. 2009;179(10):903-13.

122. Çağlı K, Turak O, Canpolat U, Özcan F, et al. Association of serum uric acid level with blood pressure variability in newly diagnosed essential hypertension. J Clin Hypertens (Greenwich). 2015;17(12):929-35.

123. Mantovani A, Rigolon R, Pichiri I, Pernigo M, et al. Hyperuricemia is associated with an increased prevalence of atrial fibrillation in hospitalized patients with type 2 diabetes. J Endocrinol Invest. 2016;39(2):159-67.

124. Huang H, Huang B, Li Y, Huang Y, et al. Uric acid and risk of heart failure: a systematic review and meta-analysis. Eur J Heart Fail. 2014;16(1):15-24.

125. Di Franco A, Cantini G, Tani A, Coppini R, et al. Sodium-dependent glucose transporters (SGLT) in human ischemic heart: a new potential pharmacological target. Int J Cardiol. 2017;243:86-90.

126. Li C, Zhang J, Xue M, Li X, et al. SGLT2 inhibition with empagliflozin attenuates myocardial oxidative stress and fibrosis in diabetic mice heart. Cardiovasc Diabetol. 2019;18(1):15.

127. Lee TM, Chang NC, Lin SZ. Dapagliflozin, a selective SGLT2 Inhibitor, attenuated cardiac fibrosis by regulating the macrophage polarization via STAT3 signaling in infarcted rat hearts. Free Radical Biol Med. 2017;104:298-310.

128. Verma S, Mazer CD, Yan AT, Mason T, et al. Effect of empagliflozin on left ventricular mass in patients with type 2 diabetes mellitus and coronary artery disease: the EMPA-HEART cardiolink-6 randomized clinical trial. Circulation. 2019;140(21):1693-702.

129. Sezai A, Sekino H, Unosawa S, Taoka M, et al. Canagliflozin for Japanese patients with chronic heart failure and type II diabetes. Cardiovasc Diabetol. 2019;18(1):76.

130. Soga F, Tanaka H, Tatsumi K, Mochizuki Y, et al. Impact of dapagliflozin on left ventricular diastolic function of patients with type 2 diabetic mellitus with chronic heart failure. Cardiovasc Diabetol. 2018;17(1):132.

131. Lee MMY, Brooksbank KJM, Wetherall K, Mangion K, et al. Effect of empagliflozin on left ventricular volumes in patients with type 2 diabetes, or prediabetes, and heart failure with reduced ejection fraction (SUGAR-DM-HF). Circulation. 2021;143(6):516-25.

132. Karasawa T, Takahashi M. Role of NLRP3 inflammasomes in atherosclerosis. J Atheroscler Thromb. 2017;24(5):443-51.

133. Lopez-Candales A, Hernández Burgos PM, Hernandez-Suarez DF,Harris D. Linking chronic inflammation with cardiovascular disease: from normal aging to the metabolic syndrome. J Nat Sci. 2017;3(4).

134. Matsumura M, Nakatani Y, Tanka S, Aoki C, et al. Efficacy of additional canagliflozin administration to type 2 diabetes patients receiving insulin therapy: examination of diurnal glycemic patterns using continuous glucose monitoring (CGM). Diabetes Ther. 2017;8(4):821-7.

135. Garvey WT, Van Gaal L, Leiter LA, Vijapurkar U, et al. Effects of canagliflozin versus glimepiride on adipokines and inflammatory biomarkers in type 2 diabetes. Metabolism. 2018;85:32-7.

136. Hattori S. Empagliflozin decreases remnant-like particle cholesterol in type 2 diabetes patients with insulin resistance. J Diabetes Investig. 2018:9(4):870-4. 
137. Tan SA, Tan L. Empagliflozin and canagliflozin attenuate inflammatory cytokines interferon-gamma, tumor necrosis factor-alpha, interleukin-6: possible mechanism of decreasing cardiovascular risk in diabetes mellitus. J Am Coll Cardiol. 2018;71(11):1830-1830.

138. Prattichizzo F, De Nigris V, Micheloni S, La Sala L, et al. Increases in circulating levels of ketone bodies and cardiovascular protection with SGLT2 inhibitors: Is low-grade inflammation the neglected component? Diabetes Obes Metab. 2018;20(11):2515-22.

139. Bonnet F, Scheen AJ. Effects of SGLT2 inhibitors on systemic and tissue low-grade inflammation: the potential contribution to diabetes complications and cardiovascular disease. Diabetes Metab. 2018;44(6):457-64.

140. Shin SJ, Chung S, Kim SJ, Lee EM, et al. Effect of sodium-glucose co-transporter 2 inhibitor, dapagliflozin, on renal renin-angiotensin system in an animal model of type 2 diabetes. PLoS ONE. 2016;11(11):e0165703.

141. Satou R, Cypress MW, Woods TC, Katsurada A, et al. Blockade of sodiumglucose cotransporter 2 suppresses high glucose-induced angiotensinogen augmentation in renal proximal tubular cells. Am J Physiol Renal Physiol. 2020;318(1):F67-f75.

142. Avogaro A, Fadini GP, Del Prato S. Reinterpreting cardiorenal protection of renal sodium-glucose cotransporter 2 inhibitors via cellular life history programming. Diabetes Care. 2020;43(3):501-7.

143. Packer M. SGLT2 inhibitors produce cardiorenal benefits by promoting adaptive cellular reprogramming to induce a state of fasting mimicry: a paradigm shift in understanding their mechanism of action. Diabetes Care. 2020;43(3):508-11.

144. Vaduganathan M, Claggett BL, Jhund PS, Cunningham JW, et al. Estimating lifetime benefits of comprehensive disease-modifying pharmacological therapies in patients with heart failure with reduced ejection fraction: a comparative analysis of three randomised controlled trials. Lancet. 2020;396(10244):121-8.

145. Gladden JD, Linke WA, Redfield MM. Heart failure with preserved ejection fraction. Pflugers Arch. 2014;466(6):1037-53.
146. Campbell RT, Jhund PS, Castagno D, Hawkins NM, et al. What have we learned about patients with heart failure and preserved ejection fraction from DIG-PEF, CHARM-preserved, and I-PRESERVE? J Am Coll Cardiol. 2012;60(23):2349-56.

147. Lam CSP, Voors AA, de Boer RA, Solomon SD, et al. Heart failure with preserved ejection fraction: from mechanisms to therapies. Eur Heart J. 2018;39(30):2780-92.

148. Zhang N, Feng B, Ma X, Sun K, et al. Dapagliflozin improves left ventricular remodeling and aorta sympathetic tone in a pig model of heart failure with preserved ejection fraction. Cardiovasc Diabetol. 2019;18(1):107.

149. Pabel S, Wagner S, Bollenberg H, Bengel $\mathrm{P}$, et al. Empagliflozin directly improves diastolic function in human heart failure. Eur J Heart Fail. 2018;20(12):1690-700.

150. Scheen AJ. Pharmacodynamics, efficacy and safety of sodium-glucose co-transporter type 2 (SGLT2) inhibitors for the treatment of type 2 diabetes mellitus. Drugs. 2015;75(1):33-59.

151. Das SR, Everett BM, Birtcher KK, Brown JM, et al. 2018 ACC expert consensus decision pathway on novel therapies for cardiovascular risk reduction in patients with type 2 diabetes and atherosclerotic cardiovascular disease: a report of the American College of Cardiology Task Force on Expert Consensus Decision Pathways. J Am Coll Cardiol. 2018;72(24):3200-23.

152. Cosentino F, Grant PJ, Aboyans V, Bailey CJ, et al. 2019 ESC Guidelines on diabetes, pre-diabetes, and cardiovascular diseases developed in collaboration with the EASD. Eur Heart J. 2020;41(2):255-323.

\section{Publisher's Note}

Springer Nature remains neutral with regard to jurisdictional claims in published maps and institutional affiliations.
Ready to submit your research? Choose BMC and benefit from:

- fast, convenient online submission

- thorough peer review by experienced researchers in your field

- rapid publication on acceptance

- support for research data, including large and complex data types

- gold Open Access which fosters wider collaboration and increased citations

- maximum visibility for your research: over 100M website views per year

At BMC, research is always in progress.

Learn more biomedcentral.com/submissions 